\title{
Administration and Therapeutic Drug Monitoring of $\beta$-lactams and Vancomycin in Critical Care Units in Colombia: The ANTIBIOCOL Study
}

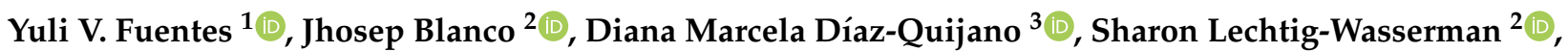 \\ Hans Liebisch-Rey ${ }^{2}(0)$, Nicolas Díaz-Pinilla ${ }^{2}$, Peter Vergara-Ramirez ${ }^{2}\left(\mathbb{C}\right.$ and Rosa-Helena Bustos ${ }^{2, *}$ \\ 1 Master's Student in Epidemiology, Faculty of Medicine, Universidad de La Sabana, Chía 140013, Colombia; \\ yulyfuba@unisabana.edu.co \\ 2 Evidence-Based Therapeutics Group, Department of Clinical Pharmacology, Faculty of Medicine, \\ Universidad de La Sabana and Clínica Universidad de La Sabana, Chía 140013, Colombia; \\ jhosepblme@unisabana.edu.co (J.B.); sharonlele@unisabana.edu.co (S.L.-W.); \\ hanslire@unisabana.edu.co (H.L.-R.); nicolasdipi@unisabana.edu.co (N.D.-P.); \\ peter.vergara@unisabana.edu.co (P.V.-R.) \\ 3 Health Research Group, Department of Epidemiology, Faculty of Medicine, Universidad de La Sabana, \\ Chía 140013, Colombia; diana.diaz1@unisabana.edu.co \\ * Correspondence: rosa.bustos@unisabana.edu.co
}

Citation: Fuentes, Y.V.; Blanco, J.; Díaz-Quijano, D.M.;

Lechtig-Wasserman, S.; Liebisch-Rey, H.; Díaz-Pinilla, N.; Vergara-Ramirez, P.; Bustos, R.-H. Administration and Therapeutic Drug Monitoring of $\beta$-lactams and Vancomycin in Critical Care Units in Colombia: The ANTIBIOCOL Study. Pharmaceutics 2021, 13, 1577. https://doi.org/ 10.3390/pharmaceutics13101577

Academic Editor: Matylda Resztak

Received: 11 August 2021

Accepted: 10 September 2021

Published: 28 September 2021

Publisher's Note: MDPI stays neutral with regard to jurisdictional claims in published maps and institutional affiliations.

Copyright: (c) 2021 by the authors. Licensee MDPI, Basel, Switzerland. This article is an open access article distributed under the terms and conditions of the Creative Commons Attribution (CC BY) license (https:// creativecommons.org/licenses/by/ $4.0 /)$.
Abstract: Therapeutic drug monitoring (TDM) and continuous infusion strategies are effective interventions in clinical practice, but these practices are still largely unknown in Colombia, especially in the critical care setting. This study aims to describe the practices involved in the administration and TDM of $\beta$-lactams and vancomycin reported by specialists in critical care in Colombia and to explore the factors that are related to the use of extended infusion. An online nationwide survey was applied to 153 specialists, who were selected randomly. A descriptive, bivariate analysis and a logistic regression model were undertaken. In total, $88.9 \%$ of the specialists reported TDM availability and $21.57 \%$ reported access to results within $6 \mathrm{~h}$. TDM was available mainly for vancomycin. We found that $85.62 \%$ of the intensivists had some type of institutional protocol; however, only $39.22 \%$ had a complete and socialized protocol. The odds of preferring extended infusions among those who did not have institutional protocols were $80 \%$ lower than those with complete protocols, OR $0.2(95 \% \mathrm{CI}$ : 0.06-0.61). The most important perceived barriers to performing continuous infusions and TDM were the lack of training and technologies. This pioneering study in Colombia could impact the quality of care and outcomes of critically ill patients in relation to the threat of antimicrobial resistance.

Keywords: drug monitoring; antimicrobial stewardship; critical care; vancomycin; beta-lactams; health care surveys; infusions; intravenous

\section{Introduction}

Antibiotic therapeutic drug monitoring (TDM) refers to the individualization of drug dosages by maintaining plasma drug concentrations within a targeted therapeutic range, which is based on pharmacokinetic (PK) and pharmacodynamic (PD) properties [1-3]. TDM could function as a tool to minimize toxicity, improve clinical efficacy and optimize antibiotic stewardship, especially in critical care settings [4,5], because this subset of patients have various PK changes, leading to either a decrease in clinical effectiveness or a higher toxicity risk [6].

Vancomycin and $\beta$-lactams are the antibiotics most frequently used and measured in plasma in the intensive care unit (ICU) setting, because of their antimicrobial spectrum and their PK/PD characteristics [7,8]. Vancomycin TDM and its use in continuous or prolonged infusion (PI) could have a beneficial effect in reaching PK targets and reducing nephrotoxicity and renal replacement therapy $[9,10]$. The area under the curve-to-minimum 
inhibitory concentration (AUC/MIC) ratio has been identified as the most appropriate pharmacokinetic/pharmacodynamic (PK/PD) target for vancomycin [9]. Rybak et al. recognized that continuous infusion may be a reasonable alternative to conventional intermittent infusion dosing when the AUC target cannot be achieved [9].

With reference to $\beta$-lactam's TDM literature status, studies have shown positive results in terms of clinical cure rates (the reduction of procalcitonin in patients with TDM follow-up), a shorter mean duration of invasive ventilation, the achievement of PK parameters and an easier dose guidance process, particularly in critically ill patients or patients undergoing renal replacement therapy $[7,11-16]$. More clinical studies should be developed to demonstrate the conclusive benefits of this practice. Furthermore, a recent meta-analysis showed that the continuous infusion of $\beta$-lactams increased the achievement of the target plasma concentrations and significantly improved the clinical cure rate [17].

Clinical practice guidelines recommend the use of extended or continuous infusions and the use of TDM with early obtainment of plasma concentration results between $24-48 \mathrm{~h}$ after the start of treatment with vancomycin or $\beta$-lactams $[7,10,18-20]$. The literature recommends the use of specialized software, as well as the reporting of the minimum inhibitory concentration (MIC) of the isolated microorganism, to generate adequate PK modeling [21-23]. Likewise, TDM and antimicrobial stewardship should be guided by an infectious disease specialist, because evidence shows that there is a positive impact on clinical outcomes, such as a reduction in mortality, a reduced length of stay, lower readmissions and costs, and a more rational use of antibiotics, when they support decision-making [24]. Among the interventions carried out in clinical practice, guiding therapy based on antibiotic institutional protocols has shown improvements in clinical outcomes, as well as reductions in the use of institutional resources, and increasing compliance with antibiotic stewardship programs [25-28]. Nonetheless, previous studies in developed countries have reported barriers such as the lack of protocols and pharmaceutical information, and the unavailability of required technologies [29-33].

Antibiotic TDM is a novel intervention which is expanding and gaining a place in clinical practice, especially in the critically ill patient context [5]. Several studies about the TDM practices (from Europe, New Zealand, and North América) have been published, with a high variability in practices, availability, and obstacles [29-33]. TDM practices and barriers in Colombia and Latin America have been explored in only one study, which used a non-representative sample [32]. Knowledge about TDM practices and barriers to its implementation is a key factor in the advancement of personalized medicine, with benefits associated with this intervention. Therefore, the main objective of this study was to describe the management practices and therapeutic monitoring of $\beta$-lactam and vancomycin, as well as to explore factors associated with the use of continuous or PI, as reported by critical care specialists in Colombia.

\section{Materials and Methods}

A descriptive cross-sectional study with an analytical component was conducted. A national survey was designed based on 12 general questions from the ANTIBIOPERF study [30] (48\% of the survey) and an additional 13 specific questions were elaborated by a multidisciplinary team of infectious disease specialists, intensivists, and epidemiologists according to the Colombian context and the objectives of this study. The appearance validity of the questionnaire was evaluated through an initial pilot test with 10 intensivists who shared comments and suggestions based on the understandability of the questions, the relevance of the questions, the response time, and the ease of browsing inside the virtual platform. The survey was adjusted according to the suggestions made and then subsequently applied to a sample of professionals in charge of adult critical care units across the country. Through the Colombian Association of Critical Medicine and Intensive Care (AMCI), the information was collected electronically by sending the survey via email to the selected specialists in the sample between October 2020 and April 2021. 
The questionnaire included 25 multiple-choice questions divided into 4 sections: sociodemographic information, clinical practice, clinical knowledge, and perception. The antibiotics chosen for the study were oxacillin, ampicillin-ampicillin/sulbactam, cefazolin, cefuroxime, ceftriaxone, ceftazidime, cefepime, piperacillin-tazobactam, meropenem, ertapenem, doripenem, and vancomycin. The types of administration were considered continuous infusions if done over $24 \mathrm{~h}$ (replacing the solution every $8-12 \mathrm{~h}$ ), PI if between 2 to $4 \mathrm{~h}$, and intermittent infusions if less than $30 \mathrm{~min}$. Each participant provided only their email address as the only personal data collected and they all voluntarily provided informed consent for the completion of the survey. To improve the response rate, participants were informed that they would enter a sweepstakes for 3 gift vouchers after the end of the study to avoid bias in the results. The resources for these incentives were provided by the researchers and do not represent any conflict of interest. This study was approved by the research and ethics subcommittee (Acta 514, 25 September 2020) of the Universidad de La Sabana.

\subsection{Study Population, Recruitment and Sample}

The target population was professionals in critical medicine and intensive care who work in one or more adult critical care units in Colombia, public or private, regardless of their first specialty. A single response per specialist was considered, based on the institution where they work most of the time. In August 2020, there were 255 specialists in critical medicine and adult intensive care throughout the country, who were registered, certified, and validated by the AMCI. From this sampling frame, for a confidence level of 95\%, a margin of error of $5 \%$ and considering a prevalence of 0.5 , the survey was carried out with 153 intensivists, chosen through a probabilistic sampling of a simple random design with a negative coordinated method. The survey was disseminated online through the SurveyMonkey ${ }^{\circledR}$ electronic platform (the instrument is available in the Supplementary Information section), and monthly reminders were emailed. Subsequently, it was verified that participants who answered the survey were the ones selected by sampling; otherwise, the answers were not considered in the statistical analysis.

\subsection{Statistical Analysis}

Data were exported from the SurveyMonkey ${ }^{\circledR}$ electronic platform to a Microsoft Excel ${ }^{\circledR}$ file and subsequently analyzed using the statistical software Rstudio ${ }^{\circledR}$ version 3.6.1 (R Development Core Team, Vienna, Austria.)

A variable of interest, entitled "approach to clinical cases", was created based on the seven questions of the clinical knowledge section of the survey (question 16-22). This variable was calculated by assigning a value of 1.5 to a correct answer for question 16-21 and a value of 0.1 to a correct answer for each of the ten vignettes of the 22 questions, giving a total score of 1 for this question. The last question (question 22) had less value because it was related to non-clinical issues that do not usually belong to the intensivist's field of experience. The final continuous score was between 0 and 10 . A dichotomous outcome variable was created based on questions 17,18 , and 20, according to the respondent's preference for using continuous infusion or PI. If a participant reported the use of continuous or prolonged infusions in $2 / 3$ or $3 / 3$ questions, they were recorded as having a preference for prolonged infusions; otherwise, they were categorized as having a preference for intermittent infusions. Correct answers were based on the literature [9,34].

Initially, a descriptive analysis of the information was performed using means and standard deviations for continuous quantitative variables with a normal distribution, and medians with interquartile ranges for continuous quantitative variables with another distribution. Categorical variables were described with absolute and relative frequencies. The association between administration practices and TDM was explored with the "approach to clinical cases" variable (Mann-Whitney U test and Kruskal-Wallis test) and a variable based on the preference for the use of continuous or prolonged infusions (Mann-Whitney $\mathrm{U}$ test and Chi-squared test). A logistic regression model was used to explore associations 
in which the preference to use continuous or PI was included as an outcome variable. Sociodemographic and clinical practice data were the independent variables. Questions about perception were excluded from the model due to their absence of biomedical and epidemiological significance [35]. Variables were adjusted to select the model that best explained the response variable ( $p$-value $<0.05$ in Wald tests). Odds ratios (ORs) were calculated based on the the exponentials of the coefficients obtained by the final model. A significance level of 0.05 and a confidence level of $95 \%$ were chosen.

\section{Results}

\subsection{Sociodemographic Information}

Of the 255 registered intensivists, 153 were selected randomly, with a response rate of $100 \%$. Participants had a median age of 43.11 years with a median of 10 years of experience; $67.97 \%$ were men; $53.59 \%$ worked in a university hospital, most of them in a medical ICU. Only $30.72 \%$ had received formal education about the use of antimicrobial therapies and $19.60 \%(30 / 153)$ did not report any type of training in this area. The participation by cities was distributed as follows: Bogotá 31.37\% (48/153); Medellin 11.11\% (17/153); Manizales and Pereira 7.19\% each (11/153); Cali 5.88\% (9/153); Cartagena and Cúcuta 3.92\% each (6/153); Bucaramanga and Sincelejo 3.27\% each (5/153); Armenia, Barranquilla, and Pasto $2.61 \%$ each (4/153); Floridablanca and Popayán $1.96 \%$ each (3/153); Montería, Neiva, and Piedecuesta 1.31\% each (2/153); and Chía, Chinchiná, Dosquebradas, Girardot, Ibagué, Magangué, Puerto Colombia, Santa Marta, Soledad, Valledupar, and Villavicencio only registered participation of 0.655 each $(1 / 153)$ (Table 1$)$.

Table 1. Descriptive analysis of sociodemographic information and clinical practice.

\begin{tabular}{|c|c|c|c|c|}
\hline \multicolumn{5}{|c|}{ Descriptive Analysis } \\
\hline Demographic & $\%$ & $\mathrm{n} / \mathrm{N}$ & Median & IQR \\
\hline Age (years) & & & 41.50 & $(34.0-50.9)$ \\
\hline$\leq 30$ & 12.42 & $19 / 153$ & & \\
\hline $31-40$ & 34.64 & $53 / 153$ & & \\
\hline $41-50$ & 28.76 & $44 / 153$ & & \\
\hline $51-60$ & 22.88 & $35 / 153$ & & \\
\hline$\geq 60$ & 1.31 & $2 / 153$ & & \\
\hline \multicolumn{5}{|c|}{ Sex } \\
\hline Men & 67.97 & $104 / 153$ & & \\
\hline Women & 32.03 & $49 / 153$ & & \\
\hline \multicolumn{5}{|c|}{ University Hospital } \\
\hline Yes & 53.59 & $82 / 153$ & & \\
\hline No & 46.41 & $71 / 153$ & & \\
\hline \multicolumn{5}{|c|}{ Type of ICU } \\
\hline Medical & 59.48 & $91 / 153$ & & \\
\hline Surgical & 9.15 & $14 / 153$ & & \\
\hline Mixed & 31.37 & $48 / 153$ & & \\
\hline \multicolumn{5}{|c|}{ Membership of the infection committee } \\
\hline Yes & 30.72 & $47 / 153$ & & \\
\hline No & 69.28 & $106 / 153$ & & \\
\hline Experience time (years) & & & 10 & $(4-17)$ \\
\hline$<5$ & 30.07 & $46 / 153$ & & \\
\hline $5-10$ & 24.84 & $38 / 153$ & & \\
\hline$>10$ & 45.10 & $69 / 153$ & & \\
\hline
\end{tabular}


Table 1. Cont.

\begin{tabular}{|c|c|c|c|c|}
\hline \multicolumn{5}{|c|}{ Descriptive Analysis } \\
\hline $\begin{array}{l}\text { Monthly dedication in ICU } \\
\text { (Hours) }\end{array}$ & & & 200 & $(160-250)$ \\
\hline$<60$ & 9.15 & $14 / 153$ & & \\
\hline $60-120$ & 9.8 & $15 / 153$ & & \\
\hline $121-200$ & 32.68 & $50 / 153$ & & \\
\hline$>200$ & 48.37 & $74 / 153$ & & \\
\hline \multicolumn{5}{|c|}{ Antimicrobial education } \\
\hline Formal & 30.72 & $47 / 153$ & & \\
\hline Informal & 49.67 & $76 / 153$ & & \\
\hline None of the Above & 19.61 & $30 / 153$ & & \\
\hline Clinical practice & $\%$ & $\mathrm{n} / \mathrm{N}$ & Median & IQR \\
\hline Infectologist Weekly visits & & & 3 & $(1-5)$ \\
\hline 0 & 7.19 & $11 / 153$ & & \\
\hline $1-4$ & 56.86 & $87 / 153$ & & \\
\hline $5-7$ & 35.95 & $55 / 153$ & & \\
\hline \multicolumn{5}{|c|}{ Institutional protocol } \\
\hline Yes & 85.62 & $131 / 153$ & & \\
\hline $\begin{array}{l}\text { Complete protocol } \\
\text { recommending PI }\end{array}$ & 39.22 & $60 / 153$ & & \\
\hline $\begin{array}{l}\text { Incomplete protocol } \\
\text { recommending PI }\end{array}$ & 35.29 & $54 / 153$ & & \\
\hline Protocol recommending II & 8.5 & $13 / 153$ & & \\
\hline Protocol without socialization & 2.61 & $4 / 153$ & & \\
\hline No & 14.38 & $22 / 153$ & & \\
\hline No protocols & 14.38 & $22 / 153$ & & \\
\hline Unnecessary & 0 & $0 / 153$ & & \\
\hline \multicolumn{5}{|c|}{ TDM availability } \\
\hline TDM not available & 11.11 & $17 / 153$ & & \\
\hline$<6 \mathrm{~h}$ & 21.57 & $33 / 153$ & & \\
\hline $6-12 \mathrm{~h}$ & 28.10 & $43 / 153$ & & \\
\hline $12-24 \mathrm{~h}$ & 9.15 & $14 / 153$ & & \\
\hline $24-48 \mathrm{~h}$ & 13.73 & $21 / 153$ & & \\
\hline$>48 \mathrm{~h}$ & 16.34 & $25 / 153$ & & \\
\hline \multicolumn{5}{|c|}{ Pharmaceutical support } \\
\hline Yes & 22.22 & $34 / 153$ & & \\
\hline No & 77.78 & $119 / 153$ & & \\
\hline \multicolumn{5}{|c|}{ Use of MIC } \\
\hline Yes & 75.82 & $116 / 153$ & & \\
\hline No & 24.18 & $37 / 153$ & & \\
\hline \multicolumn{5}{|c|}{ Use of software } \\
\hline Yes & 26.80 & $41 / 153$ & & \\
\hline No & 73.20 & $112 / 153$ & & \\
\hline \multicolumn{5}{|c|}{ Prolonged infusions } \\
\hline Yes & 71.90 & $110 / 153$ & & \\
\hline No & 28.10 & $43 / 153$ & & \\
\hline \multicolumn{3}{|c|}{ Approach of clinical cases } & 4.9 & $(3.5-6.4)$ \\
\hline
\end{tabular}

PI: prolonged infusions, II: intermittent infusions. 


\subsection{Clinical Approach}

Of the specialists, $88.9 \%$ reported TDM availability and $21.57 \%$ made known access to results within $6 \mathrm{~h}$. The main available antibiotic TDM was vancomycin $(75.82 \%)$, with a low proportion of $\beta$-lactams TDM (Figure 1).

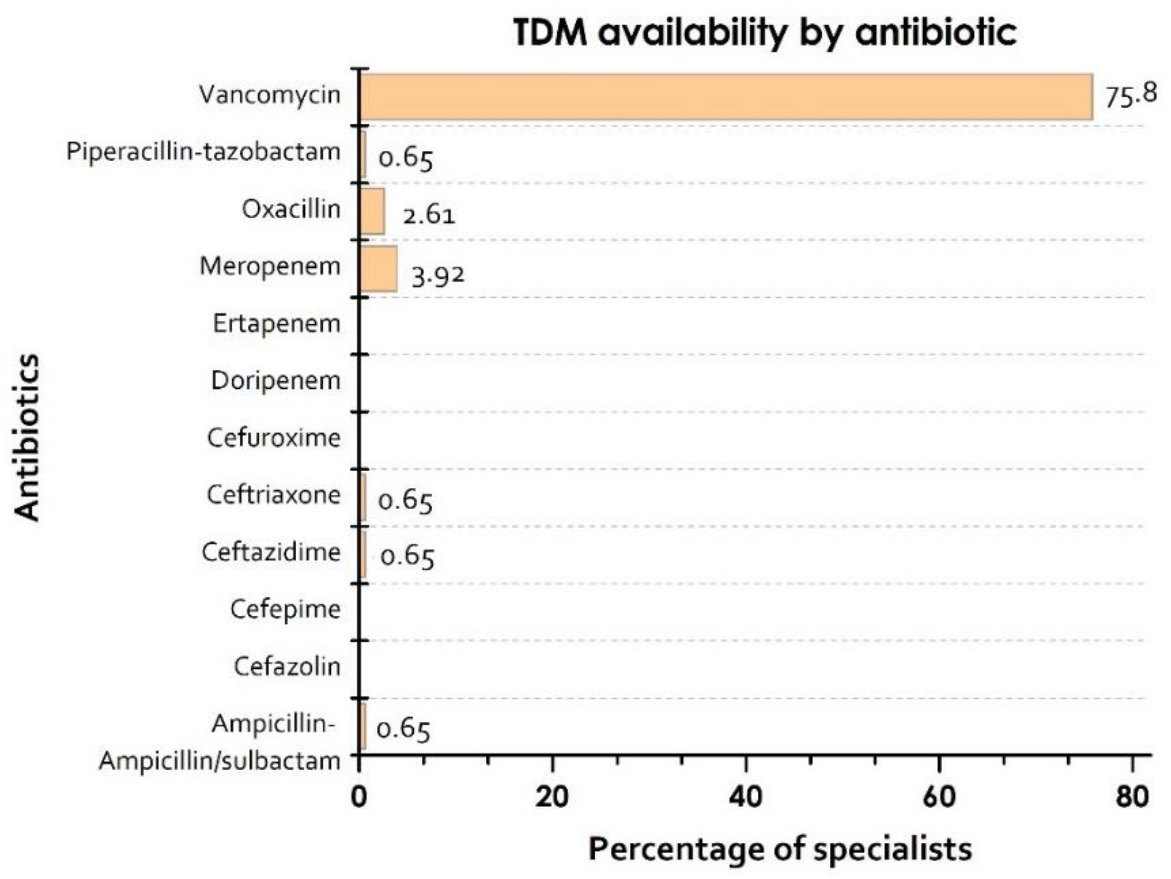

Figure 1. Antibiotics in which serum concentrations can be controlled according to availability in the hospital where the specialists work. TDM: therapeutic drug monitoring.

Of the specialists, $22.2 \%$ reported pharmaceutical support, with a median of 3 visits per week of the infectious disease specialists. The results showed that 131/153 (85.62\%) of the intensivists had some type of institutional protocol; however, only $39.22 \%$ had a complete and socialized protocol. Likewise, the specialists who have protocols in their institution but without information related to the stability of the drugs (incomplete protocols) represented $35.29 \%$ of the total of specialists surveyed (54/153) (Table 1). In $8.5 \%$ of the institutions where specialists work, they recommend the use of II in their protocols. No specialists considered institutional protocols to be unnecessary $(0 / 153)$ and $2.61 \%$ reported that the existing protocols in their institution were not socialized to health professionals and were therefore unknown (Figure 2).

We found that $71.9 \%$ of the intensivists involved in the study preferred prolonged or continuous infusions. The median of the clinical cases approach score was $4.9 / 10$, obtained based on the sum of the scores of each question regarding the loading dose and preference as to the use of PI in clinical cases and PK/PD targets. Only 10 people obtained a score greater than eight (the highest was 9.55). In regard to these questions, $33.33 \%$ of intensivists $(51 / 153)$ reported the use of $\beta$-lactam loading doses for all types of infusions in cases of severe infections, compared to $20.26 \%(31 / 153)$ who said they never used them. The clinical case in which there were more incorrect answers was the prescription of vancomycin for bacteremia with MRSA and sepsis, at $72.54 \%(110 / 153)$, and the clinical case that had the most correct answers was the prescription of piperacillin-tazobactam for urinary tract infection by Pseudomonas aeruginosa and sepsis, with $78.43 \%$ (120/153). Regarding the objective value of the area under the curve over the minimum inhibitory concentration (AUC24/MIC) in critically ill patients with methicillin-resistant Staphylococcus aureus infections, only $54.24 \%(83 / 153)$ gave the correct answer (400-600 $\mathrm{mg} \mathrm{H} / \mathrm{L})$. In regard to the last question, regarding the maximum number of hours (in optimal conditions) that an antibiotic is stable in an infusion solution, meropenem was the antibiotic on which the 
intensivists had the most knowledge, with 40.52\% (62/153), and cefazolin was the one that they knew the least, at $11.11 \%(17 / 153)$.

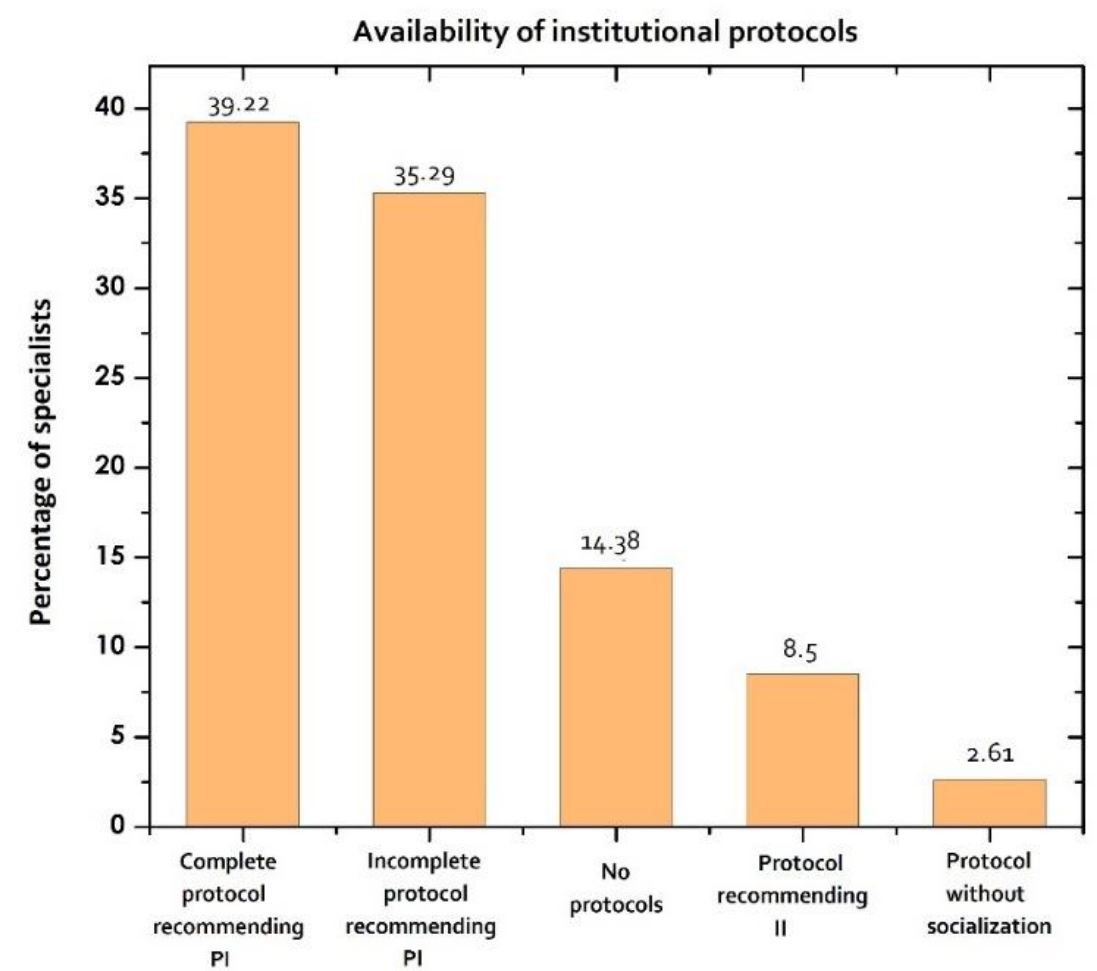

Answers

Figure 2. Characterization of the availability of institutional protocols to guide clinical practice. Complete protocols refer to those with additional information (product stability, dilution method and solution, maximum concentrations, duration of infusion, incompatibilities). PI: prolonged infusions, II: intermittent infusions.

\subsection{Attitudes and Barriers towards Prolonged/Continuous Infusions and TDM}

The main perceived barrier for choosing continuous or PI was the lack of training of personnel in this practice $(35.29 \%)$. On the other hand, $56.21 \%$ of those surveyed considered that the lack of technologies for measuring antibiotic levels was the main barrier to performing TDM in their hospitals. Finally, most intensivists $(69.28 \%)$ considered that the prolonged and continuous infusion of vancomycin and $\beta$-lactams improved the prognosis of patients with severe sepsis and that the scientific evidence pointed in this direction (Figure 3).

\subsection{Factors Associated with the Use of Prolonged/Continuous Infusions}

Regarding the bivariate approach, crude analysis suggested an association between the use of institutional protocols and TDM availability with the score obtained by the "approach to clinical cases" ( $p$-value < 0.05) (Table 2). Initially, no association was found between sociodemographic and clinical practice variables with a preference for using continuous infusions or PIs (Table 3). Our findings suggest that clinical practice based on institutional protocols could explain the preference for using continuous infusions or PIs, as the odds of preferring continuous or extended infusions among those who did not have institutional protocols was $80 \%$ lower compared with those who had comprehensive protocols that recommend PI; OR 0.2 (CI95\%: 0.06-0.61), $p$-value < 0.05. Similarly, the odds of using PI among those who had incomplete protocols was $65 \%$ lower than it was among those who had comprehensive protocols; OR 0.35 (CI95\%: 0.14-0.87), $p$-value < 0.05. 

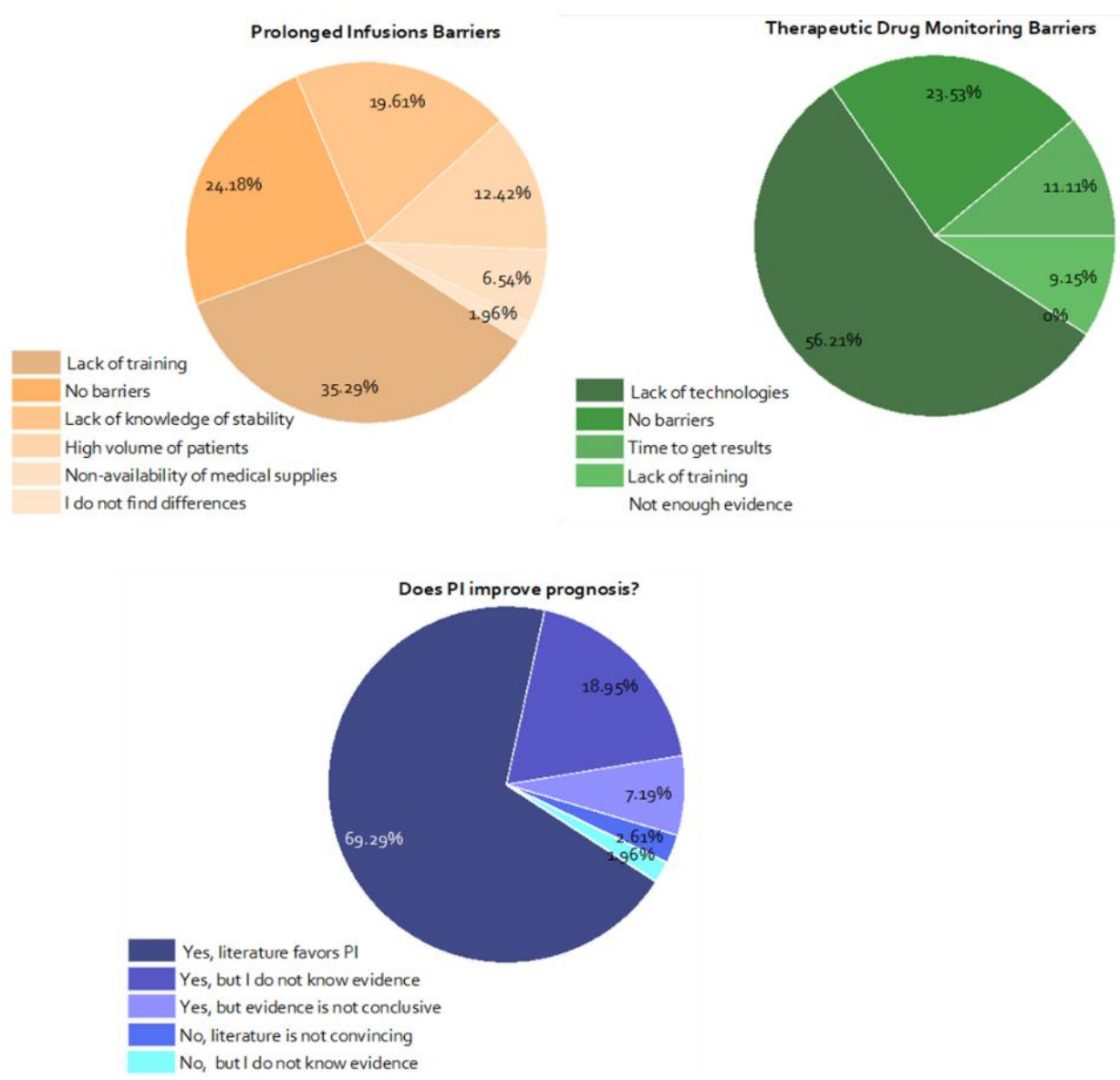

Figure 3. Perception of specialists on types of barriers related to prolonged infusions, TDM, and knowledge of the evidence. PI: prolonged infusions, II: intermittent infusions.

Table 2. Bivariate analysis of approaches to clinical cases.

\begin{tabular}{ccc}
\hline & \multicolumn{2}{c}{ Bivariate Analysis } \\
\hline & Median (IQR) & $p$-value \\
\hline Male & $5.0(4.4,6.4)$ & \\
\hline Female & $4.9(4.2,6.4)$ & 0.501 \\
\hline Yes & University hospital & \multirow{2}{*}{0.946} \\
\hline No & $4.9(3.4,6.4)$ & \\
\hline Yes & $4.8(4.3,6.2)$ & 0.650 \\
\hline No & Membership of the infection committee & \\
\hline & $4.7(3.3,6.6)$ & \\
\hline Formal education & $4.9(4.2,6.3)$ & \\
\hline Informal education & Antimicrobial education & \\
\hline None & $4.9(4.2,6.4)$ & \\
\hline
\end{tabular}


Table 2. Cont.

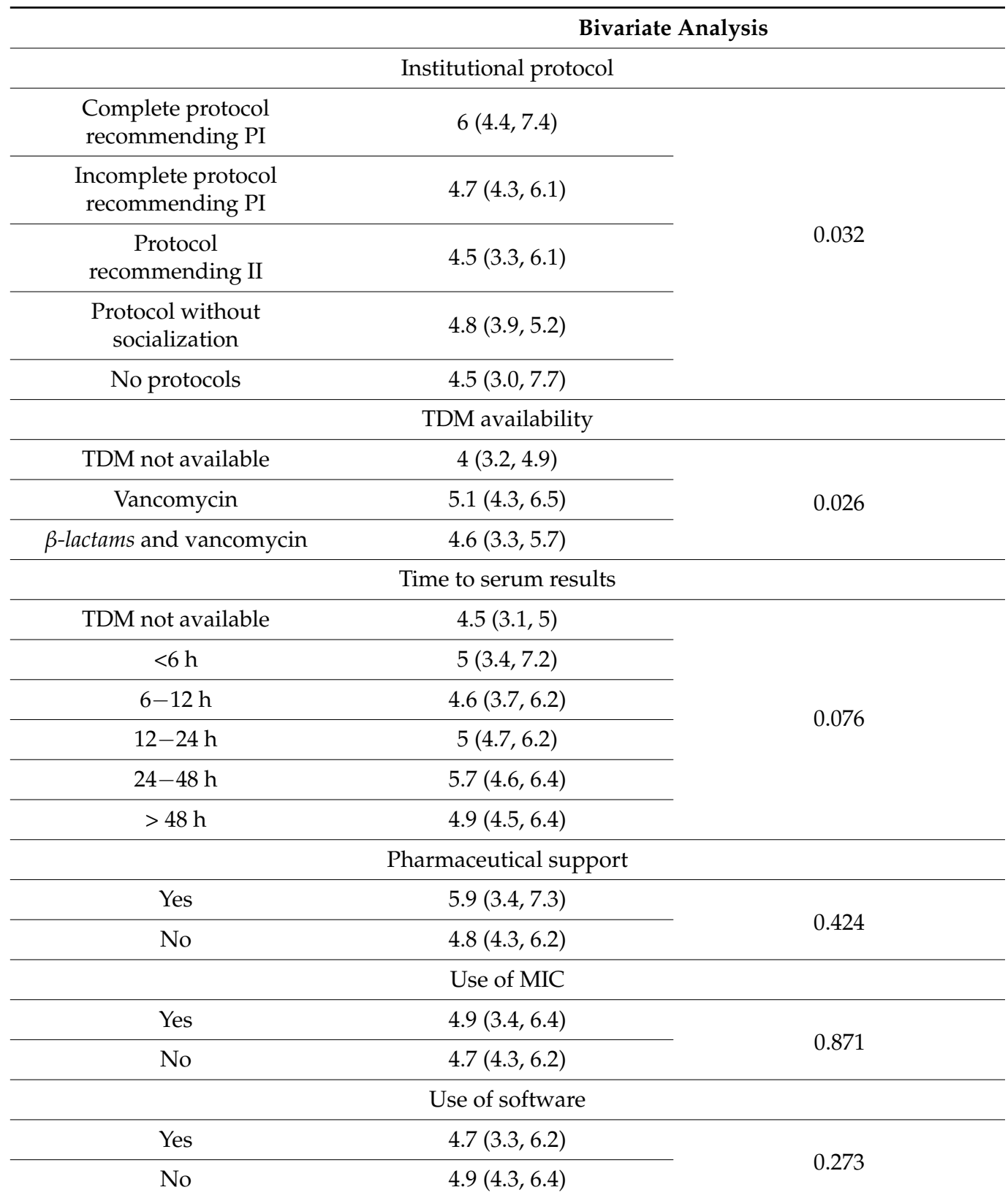

PI: prolonged infusions, II: intermittent infusions.

Table 3. Bivariate analysis of preferences for the use of continuous or prolonged infusions.

\begin{tabular}{|c|c|c|c|}
\hline & \multicolumn{3}{|c|}{ Bivariate Analysis } \\
\hline & PI $n=110$ & II $n=43$ & $p$-value \\
\hline \multicolumn{4}{|c|}{ Age, median years (IQR) } \\
\hline & $41.2(34.1,50.6)$ & $45.4(34.2,55.6)$ & 0.447 \\
\hline \multicolumn{4}{|c|}{ Sex, $n(\%)$} \\
\hline Male & $76(69)$ & $28(65.1)$ & \multirow{2}{*}{0.778} \\
\hline Female & $34(30.9)$ & $15(34.9)$ & \\
\hline \multicolumn{4}{|c|}{ University hospital, $n(\%)$} \\
\hline
\end{tabular}


Table 3. Cont.

\begin{tabular}{|c|c|c|c|}
\hline \multirow[b]{2}{*}{ Yes } & \multicolumn{3}{|c|}{ Bivariate Analysis } \\
\hline & $62(56.4)$ & $20(46.5)$ & \multirow{2}{*}{0.358} \\
\hline No & $48(43.6)$ & $23(53.5)$ & \\
\hline \multicolumn{4}{|c|}{ Membership of the infection committee, $n(\%)$} \\
\hline Yes & $35(31.8)$ & $12(27.9)$ & \multirow{2}{*}{0.782} \\
\hline No & $75(68.2)$ & $31(72.1)$ & \\
\hline \multicolumn{4}{|c|}{ Experience time, median years (IQR) } \\
\hline & $10(4,16.7)$ & $8(3,17.5)$ & 0.205 \\
\hline \multicolumn{4}{|c|}{ Monthly dedication in ICU, median hours (IQR) } \\
\hline & $240(160,280)$ & $200(160,240)$ & 0.159 \\
\hline \multicolumn{4}{|c|}{ Antimicrobial education, $n(\%)$} \\
\hline Formal education & $30(27.3)$ & $17(39.5)$ & \multirow{3}{*}{0.32} \\
\hline Informal education & $58(52.7)$ & $18(41.9)$ & \\
\hline None & $22(20)$ & $8(18.6)$ & \\
\hline \multicolumn{4}{|c|}{ Infectologist weekly visits, median days (IQR) } \\
\hline & $3(1,5)$ & $3(1,7)$ & 0.675 \\
\hline \multicolumn{4}{|c|}{ Institutional protocol, $n(\%)$} \\
\hline $\begin{array}{l}\text { Complete protocol } \\
\text { recommending PI }\end{array}$ & $50(45.5)$ & $10(23.3)$ & \multirow{5}{*}{0.093} \\
\hline $\begin{array}{l}\text { Incomplete protocol } \\
\text { recommending PI }\end{array}$ & $36(32.7)$ & $18(41.9)$ & \\
\hline $\begin{array}{c}\text { Protocol } \\
\text { recommending II }\end{array}$ & $9(8.2)$ & $4(9.3)$ & \\
\hline $\begin{array}{l}\text { Protocol without } \\
\text { socialization }\end{array}$ & $3(2.7)$ & $1(2.3)$ & \\
\hline No protocols & $12(10.9)$ & $10(23.2)$ & \\
\hline \multicolumn{4}{|c|}{ TDM availability, $n(\%)$} \\
\hline TDM not available & $23(20.9)$ & $15(34.9)$ & \multirow{3}{*}{0.102} \\
\hline Vancomycin & $81(73.6)$ & $24(55.8)$ & \\
\hline $\begin{array}{l}\beta \text {-lactams and } \\
\text { vancomycin }\end{array}$ & $6(5.5)$ & $4(9.3)$ & \\
\hline \multicolumn{4}{|c|}{ Time to serum results, $n(\%)$} \\
\hline TDM not available & $20(18.2)$ & $13(30.2)$ & \multirow{6}{*}{0.538} \\
\hline$<6 \mathrm{~h}$ & $31(28.2)$ & $12(27.9)$ & \\
\hline $6-12 \mathrm{~h}$ & $10(9.1)$ & $4(9.3)$ & \\
\hline $12-24 \mathrm{~h}$ & $15(13.6)$ & $6(13.9)$ & \\
\hline $24-48 \mathrm{~h}$ & $21(19.1)$ & $4(9.3)$ & \\
\hline$>48 \mathrm{~h}$ & $13(11.8)$ & $4(9.3)$ & \\
\hline
\end{tabular}


Table 3. Cont.

\begin{tabular}{|c|c|c|c|}
\hline \multicolumn{4}{|c|}{ Bivariate Analysis } \\
\hline \multicolumn{4}{|c|}{ Pharmaceutical support, $n(\%)$} \\
\hline Yes & $27(24.5)$ & $7(16.3)$ & \multirow{2}{*}{0.373} \\
\hline No & $83(75.4)$ & $36(83.7)$ & \\
\hline \multicolumn{4}{|c|}{ Use of MIC, $n(\%)$} \\
\hline Yes & $83(75.5)$ & $33(76.7)$ & \multirow{2}{*}{1} \\
\hline No & $27(24.5)$ & $10(23.3)$ & \\
\hline \multicolumn{4}{|c|}{ Use of software, $n(\%)$} \\
\hline Yes & $28(25.5)$ & $13(30.2)$ & \multirow{2}{*}{0.691} \\
\hline No & $82(74.5)$ & $30(69.8)$ & \\
\hline
\end{tabular}

PI: prolonged infusions, II: intermittent infusions.

\section{Discussion}

ANTIBIOCOL was the first nationwide survey evaluating the administration of prolonged and continuous infusions and drug monitoring of $\beta$-lactams and vancomycin in ICU settings in Colombia, representing an approach towards understanding the preferences and decisions made by critical care specialists in their daily practice. Its results could impact clinical practice, quality of care, and possibly the outcomes of critically ill patients within the framework of the antimicrobial stewardship strategies.

In our study, most of the participants were men between the ages of 21 and 40 in a 2:1 ratio compared to women, with informal education about antimicrobial stewardship, a median clinical experience of 10 years, and a monthly dedication of approximately $200 \mathrm{~h}$, which demonstrated a high level of experience and workload. The origins of the surveyed physicians were diverse and included the main cities of Colombia, which shows that the random selection of the participants allowed the inclusion of different geographic territories and different levels of clinical experience.

Concerning administration practices, the majority of participants considered that a prolonged or continuous infusion of beta-lactam antibiotics and vancomycin improved the prognosis of their patients, and this is sustained by current evidence. This information is consistent with the proportion of physicians that use continuous infusion in Colombia $(71.9 \%)$. Nevertheless, there are still many physicians who prefer bolus infusions over prolonged or continuous infusions, and this finding correlates with the lack of training of medical staff in this practice. We can find similar results in France, where $77 \%$ of the participants were convinced of the value of using continuous infusion for $\beta$-lactams and vancomycin above other administration methods [29]. Nonetheless, several studies in the United Kingdom evidenced a lower preference for this type of infusion (as low as 20\%), although the evidence was in favor of its use, which places Colombia in an encouraging prospect $[17,36,37]$.

Regarding TDM, we conclude that performing TDM for $\beta$-lactams remains an underused practice in Colombia, with the usage of TDM restricted to vancomycin and only in some cases to $\beta$-lactams, such as meropenem, piperacillin tazobactam, ampicillin sulbactam, and ceftazidime. Similar findings were obtained in other studies, especially in the only paper that included countries from Latin America [32]. Other studies have shown interesting results regarding antibiotic stewardship programs and TDM use, such as the study performed by Kim B et al., which demonstrated that, even in hospitals with antibiotic stewardship programs, TDM is still an underused practice, especially for $\beta$-lactams [38]. In our findings, a lack of technology was the main barrier reported by the participants. Since Colombia is still a developing country, the lack of technology in our hospitals is a common but concerning issue, leading physicians to work on the basis of the availability of supplies, rather than by following clinical guidelines. 
Not only is the availability of TDM among the hospitals vital, so are the waiting times between sampling and the obtainment of results. Our study showed that results took more than $24 \mathrm{~h}$ to arrive in $30 \%$ of the reports. This should be considered another barrier to the use of TDM, since long waiting times to receive the results discourage clinicians from performing it; the main objective of TDM usage is to optimize dosing, meaning that results should be immediately available or at least take less than $24 \mathrm{~h}$ to enable decision-making as quickly as possible. Another obstacle found was the general knowledge gap regarding the use of continuous infusions in real clinical contexts, as well as PK/PD therapeutic targets and the stability of antibiotics, which could be explained by the lack of technology in many cases, because the evidence is recent and there are no clinical practice guidelines at a national level.

Even though conducting an analytical exploration was not the main objective, striking data were found. The main analytical result of this research indicates that the availability of complete institutional protocols with additional information significantly predicts the preference for continuous infusion and PI by intensivists. The availability of these protocols, even if they were incomplete, was above the values reported in other studies [28-32]. These results demonstrate the importance of having internal protocols in ICUs as a standardized method to improve clinical practices, such as choosing the right antibiotic, time, dosing, and the best method of administration. Furthermore, this confirms the need for unifying the national protocols to have an even more consistent clinical practice guidelines that could improve clinical outcomes.

This is a cross-sectional study that has limitations in determining causal association. In consequence, this research is an initial approach to describing practices and barriers, suggest possible action areas, and acting as the starting point for future research. Moreover, due to the absence of a list of every intensive care specialist in the country, the selection of the sample was made through the specialists registered in the AMCI, which is recognized as a limitation of this study. Additionally, non-significant results do not necessarily indicate a lack of association but may be due to the sample size that was initially calculated to obtain proportions (lack of statistical power). However, despite the above, the significant associations found reflect the strength of the association. Another strength of this study is the representativeness of the random sample that support the external validity of the study for Colombia, which included big and small cities, unlike similar studies from other countries that performed convenience sampling.

This study is the first of its type in a Latin American country and included the design of a survey adapted to the Colombian context and its needs, as well as addressing barriers pertaining to public health decision-making. In addition, this study can provide a starting point for further research regarding the correct methods used to perform TDM of $\beta$-lactams, vancomycin, and other antibiotic groups in the ICU setting. Likewise, future experimental or observational research should be carried out to assess clinical outcomes with the implementation of protocols involving continuous infusion and TDM practices, along with encouraging physicians to follow clinical guidelines or internal protocols to increase the accuracy of antimicrobial use among critically ill patients. Considering the barriers found among clinicians concerning the use of continuous or extended infusions, these should also be assessed in order to achieve higher rates of clinical cures and to reduce toxicity based on the available evidence on this practice.

\section{Conclusions}

This present paper is the first of its class in Colombia, involving a representative sample of intensive care specialists with vast clinical experience, who recognize continuous infusions as the preferred administration strategy to improve the prognosis of patients. Vancomycin was the most frequently monitored antibiotic and, for the most part, TDM for $\beta$-lactams was not available, which reflects a lack of relevant technologies in the country, recognized by specialists as the main barrier for its use. This technological gap not only affects the applicability of the evidence in the clinical context, but also impacts the degree 
of general knowledge about these practices. Other hurdles, such as scarce training and socialization of complete protocols, predict the possibility of choosing this type of administration for antibiotics. The findings described above may facilitate the development of interventions that influence these practices and the outcomes of critically ill patients, in favor of current antimicrobial stewardship strategies.

Supplementary Materials: The following are available online at https:/ /www.mdpi.com/article/10 .3390/pharmaceutics13101577/s1, ANTIBIOCOL study questionnaire.

Author Contributions: Conceptualization Y.V.F., D.M.D.-Q., R.-H.B., J.B. and P.V.-R.; methodology Y.V.F., D.M.D.-Q., J.B., S.L.-W., H.L.-R. and N.D.-P.; writing-original draft preparation, Y.V.F., J.B., S.L.-W., H.L.-R. and N.D.-P.; writing-review and editing, D.M.D.-Q., R.-H.B.; P.V.-R. and J.B.; supervision, D.M.D.-Q. and R.-H.B.; project administration, R.-H.B. and J.B.; funding acquisition, R.-H.B. and J.B. All authors have read and agreed to the published version of the manuscript.

Funding: This research was funded by The Ministry of Science, Technology, and InnovationMinciencias (Contract No. 906/2019) call number 850-2019 “Call for the strengthening of CTel projects in Medical and Health Sciences with young talent and regional impact"-MED-228-2018.

Institutional Review Board Statement: This study was approved by the research and ethics subcommittee of the Universidad de La Sabana (Acta 514, 25 September 2020).

Informed Consent Statement: The survey had a heading related to informed consent and ethical aspects of this research. By completing the survey, participants voluntarily accepted participation. To improve the response rate, participants were informed that they would enter a sweepstakes for $3 \mathrm{gift}$ vouchers after the end of the study to avoid bias in the results. The resources for these incentives were provided by the researchers and do not represent any conflict of interest.

Acknowledgments: We would like to thank José Luis Accini of the Colombian Association of Critical Medicine and Intensive Care (AMCI) for assistance with developing our study and Javier David Trujillo for his invaluable support in the collection and compilation of data.

Conflicts of Interest: The authors declare no conflict of interest. The funders had no role in the design of the study; in the collection, analyses, or interpretation of data; in the writing of the manuscript, or in the decision to publish the results.

\section{References}

1. Garzon, V.; Bustos, R.H.; Pinacho, D.G. Personalized Medicine for Antibiotics: The Role of Nanobiosensors in Therapeutic Drug Monitoring. J. Pers. Med. 2020, 10, 147. [CrossRef]

2. Kang, J.S.; Lee, M.H. Overview of therapeutic drug monitoring. Korean J. Intern. Med. 2009, 24, 1-10. [CrossRef]

3. Osorio, C.; Garzon, L.; Jaimes, D.; Silva, E.; Bustos, R.H. Impact on Antibiotic Resistance, Therapeutic Success, and Control of Side Effects in Therapeutic Drug Monitoring (TDM) of Daptomycin: A Scoping Review. Antibiotics 2021, 10, 263. [CrossRef]

4. Barlam, T.F.; Cosgrove, S.E.; Abbo, L.M.; MacDougall, C.; Schuetz, A.N.; Septimus, E.J.; Srinivasan, A.; Dellit, T.H.; Falck-Ytter, Y.T.; Fishman, N.O.; et al. Implementing an Antibiotic Stewardship Program: Guidelines by the Infectious Diseases Society of America and the Society for Healthcare Epidemiology of America. Clin. Infect. Dis. 2016, 62, e51-e77. [CrossRef] [PubMed]

5. Roberts, J.A.; Norris, R.; Paterson, D.L.; Martin, J.H. Therapeutic drug monitoring of antimicrobials. Br. J. Clin. Pharmacol. 2012, 73, 27-36. [CrossRef] [PubMed]

6. Udy, A.A.; Roberts, J.A.; Lipman, J. Clinical implications of antibiotic pharmacokinetic principles in the critically ill. Intensive Care Med. 2013, 39, 2070-2082. [CrossRef] [PubMed]

7. Fratoni, A.J.; Nicolau, D.P.; Kuti, J.L. A guide to therapeutic drug monitoring of beta-lactam antibiotics. Pharmacotherapy 2021, 41, 220-233. [CrossRef]

8. Park, S.J.; Lim, N.R.; Park, H.J.; Yang, J.W.; Kim, M.J.; Kim, K.; In, Y.W.; Lee, Y.M. Evaluation of risk factors for vancomycin-induced nephrotoxicity. Int. J. Clin. Pharm. 2018, 40, 1328-1334. [CrossRef]

9. Rybak, M.J.; Le, J.; Lodise, T.P.; Levine, D.P.; Bradley, J.S.; Liu, C.; Mueller, B.A.; Pai, M.P.; Wong-Beringer, A.; Rotschafer, J.C.; et al. Therapeutic monitoring of vancomycin for serious methicillin-resistant Staphylococcus aureus infections: A revised consensus guideline and review by the American Society of Health-System Pharmacists, the Infectious Diseases Society of America, the Pediatric Infectious Diseases Society, and the Society of Infectious Diseases Pharmacists. Am. J. Health-Syst. Pharm. 2020, 77, 835-864.

10. Wysocki, M.; Delatour, F.; Faurisson, F.; Rauss, A.; Pean, Y.; Misset, B.; Thomas, F.; Timsit, J.F.; Similowski, T.; Mentec, H.; et al. Continuous versus intermittent infusion of vancomycin in severe Staphylococcal infections: Prospective multicenter randomized study. Antimicrob. Agents Chemother. 2001, 45, 2460-2467. [CrossRef] 
11. De Waele, J.J.; Carrette, S.; Carlier, M.; Stove, V.; Boelens, J.; Claeys, G.; Leroux-Roels, I.; Hoste, E.; Depuydt, P.; Decruyenaere, J.; et al. Therapeutic drug monitoring-based dose optimisation of piperacillin and meropenem: A randomised controlled trial. Intensive Care Med. 2014, 40, 380-387. [CrossRef]

12. Economou, C.J.P.; Wong, G.; McWhinney, B.; Ungerer, J.P.J.; Lipman, J.; Roberts, J.A. Impact of $\beta$-lactam antibiotic therapeutic drug monitoring on dose adjustments in critically ill patients undergoing continuous renal replacement therapy. Int. J. Antimicrob. Agents 2017, 49, 589-594. [CrossRef]

13. Fournier, A.; Eggimann, P.; Pagani, J.L.; Revelly, J.P.; Decosterd, L.A.; Marchetti, O.; Pannatier, A.; Voirol, P.; Que, Y.A. Impact of the introduction of real-time therapeutic drug monitoring on empirical doses of carbapenems in critically ill burn patients. Burn. J. Int. Soc. Burn. Injuries 2015, 41, 956-968. [CrossRef] [PubMed]

14. Lechtig-Wasserman, S.; Liebisch-Rey, H.; Diaz-Pinilla, N.; Blanco, J.; Fuentes-Barreiro, Y.V.; Bustos, R.H. Carbapenem Therapeutic Drug Monitoring in Critically Ill Adult Patients and Clinical Outcomes: A Systematic Review with Meta-Analysis. Antibiotics 2021, 10, 177. [CrossRef] [PubMed]

15. McDonald, C.; Cotta, M.O.; Little, P.J.; McWhinney, B.; Ungerer, J.P.; Lipman, J.; Roberts, J.A. Is high-dose $\beta$-lactam therapy associated with excessive drug toxicity in critically ill patients? Minerva Anestesiol. 2016, 82, 957-965.

16. Richter, D.C.; Dietrich, M.; Lalev, L.D.; Schmitt, F.C.F.; Fiedler, M.O.; Bruckner, T.; Stoerzinger, D.; Chiriac, U.; Klein, S.; Hackert, T.; et al. Prolonged Infusion of $\beta$-lactams Decreases Mortality in Patients with Septic Shock: A Retrospective before-andafter Study. Antibiotics 2021, 10, 687. [CrossRef]

17. Kondo, Y.; Ota, K.; Imura, H.; Hara, N.; Shime, N. Prolonged versus intermittent beta-lactam antibiotics intravenous infusion strategy in sepsis or septic shock patients: A systematic review with meta-analysis and trial sequential analysis of randomized trials. J. Intensive Care 2020, 8, 77. [CrossRef]

18. Guilhaumou, R.; Benaboud, S.; Bennis, Y.; Dahyot-Fizelier, C.; Dailly, E.; Gandia, P.; Goutelle, S.; Lefeuvre, S.; Mongardon, N.; Roger, C.; et al. Optimization of the treatment with beta-lactam antibiotics in critically ill patients-guidelines from the French Society of Pharmacology and Therapeutics (Societe Francaise de Pharmacologie et Therapeutique-SFPT) and the French Society of Anaesthesia and Intensive Care Medicine (Societe Francaise d'Anesthesie et Reanimation-SFAR). Crit. Car. 2019, $23,104$.

19. Rybak, M.J.; Le, J.; Lodise, T.P.; Levine, D.P.; Bradley, J.S.; Liu, C.; Mueller, B.A.; Pai, M.P.; Wong-Beringer, A.; Rotschafer, J.C.; et al. Therapeutic Monitoring of Vancomycin for Serious Methicillin-resistant Staphylococcus aureus Infections: A Revised Consensus Guideline and Review by the American Society of Health-system Pharmacists, the Infectious Diseases Society of America, the Pediatric Infectious Diseases Society, and the Society of Infectious Diseases Pharmacists. Clin. Infect. Dis. 2020, 71, 1361-1364. [PubMed]

20. Ye, Z.K.; Li, C.; Zhai, S.D. Guidelines for therapeutic drug monitoring of vancomycin: A systematic review. PLoS ONE 2014, 9, e99044. [CrossRef] [PubMed]

21. Felton, T.W.; Hope, W.W.; Roberts, J.A. How severe is antibiotic pharmacokinetic variability in critically ill patients and what can be done about it? Diagn Microbiol. Infect. Dis. 2014, 79, 441-447. [CrossRef]

22. Fuchs, A.; Csajka, C.; Thoma, Y.; Buclin, T.; Widmer, N. Benchmarking therapeutic drug monitoring software: A review of available computer tools. Clin. Pharmacokinet. 2013, 52, 9-22. [CrossRef]

23. Veiga, R.P.; Paiva, J.A. Pharmacokinetics-pharmacodynamics issues relevant for the clinical use of beta-lactam antibiotics in critically ill patients. Crit. Care 2018, 22, 233. [CrossRef]

24. McQuillen, D.P.; MacIntyre, A.T. The Value That Infectious Diseases Physicians Bring to the Healthcare System. J. Infect. Dis. 2017, 216, S588-S593. [CrossRef]

25. Macheda, G.; Luc, A.; Beraud, G.; Castan, B.; Gauzit, R.; Lesprit, P.; Tattevin, P.; Thilly, N.; Pulcini, C. Impact of the French Infectious Diseases Society's (SPILF) proposals for shorter antibiotic therapies. Med. Mal. Infect. 2019, 49, 456-462. [CrossRef]

26. Marrie, T.J.; Lau, C.Y.; Wheeler, S.L.; Wong, C.J.; Vandervoort, M.K.; Feagan, B.G. A controlled trial of a critical pathway for treatment of community-acquired pneumonia. CAPITAL Study Investigators. Community-Acquired Pneumonia Intervention Trial Assessing Levofloxacin. JAMA 2000, 283, 749-755. [CrossRef] [PubMed]

27. Roger, P.M.; Michelangeli, C.; Girard, D.; Etienne, P.; Borredon, G.; Dautezac, V.; Keita-Perse, O.; Del Giudice, P. Streamlined guidelines for antibiotic therapies are required for greater efficacy. Med. Mal. Infect. 2019, 49, 363-366. [CrossRef] [PubMed]

28. Spivak, E.S.; Cosgrove, S.E.; Srinivasan, A. Measuring Appropriate Antimicrobial Use: Attempts at Opening the Black Box. Clin. Infect. Dis. 2016, 63, 1639-1644. [PubMed]

29. Buyle, F.M.; Decruyenaere, J.; De Waele, J.; Tulkens, P.M.; Van Audenrode, T.; Depuydt, P.; Claeys, G.; Robays, H.; Vogelaers, D. A survey of beta-lactam antibiotics and vancomycin dosing strategies in intensive care units and general wards in Belgian hospitals. Eur. J. Clin. Microbiol. Infect. Dis. 2013, 32, 763-768. [CrossRef] [PubMed]

30. Charmillon, A.; Novy, E.; Agrinier, N.; Leone, M.; Kimmoun, A.; Levy, B.; Demore, B.; Dellamonica, J.; Pulcini, C. The ANTIBIOPERF study: A nationwide cross-sectional survey about practices for beta-lactam administration and therapeutic drug monitoring among critically ill patients in France. Clin. Microbiol. Infect. 2016, 22, 625-631. [CrossRef] [PubMed]

31. Liebchen, U.; Paal, M.; Scharf, C.; Schroeder, I.; Grabein, B.; Zander, J.; Siebers, C.; Zoller, M. The ONTAI study-a survey on antimicrobial dosing and the practice of therapeutic drug monitoring in German intensive care units. J. Crit. Care 2020, 60, 260-266. [CrossRef] [PubMed] 
32. Tabah, A.; De Waele, J.; Lipman, J.; Zahar, J.R.; Cotta, M.O.; Barton, G.; Timsit, J.F.; Roberts, J.A.; Working Group for Antimicrobial Use in the ICU within the Infection Section of the European Society of Intensive Care Medicine (ESICM). The ADMIN-ICU survey: A survey on antimicrobial dosing and monitoring in ICUs. J. Antimicrob. Chemother. 2015, 70, 2671-2677. [CrossRef] [PubMed]

33. Wong, G.; Brinkman, A.; Benefield, R.J.; Carlier, M.; De Waele, J.J.; El Helali, N.; Frey, O.; Harbarth, S.; Huttner, A.; McWhinney, B.; et al. An international, multicentre survey of beta-lactam antibiotic therapeutic drug monitoring practice in intensive care units. J. Antimicrob. Chemother. 2014, 69, 1416-1423. [CrossRef] [PubMed]

34. Longuet, P.; Lecapitaine, A.L.; Cassard, B.; Batista, R.; Gauzit, R.; Lesprit, P.; Haddad, R.; Vanjak, D.; Diamantis, S. Preparing and administering injectable antibiotics: How to avoid playing God. Med. Mal. Infect. 2016, 46, 242-268. [CrossRef]

35. Porta, M. A Dictionary of Epidemiology, 6th ed.; Oxford University Press: Oxford, UK, 2016.

36. Barton, G.J.; Morecroft, C.W.; Henney, N.C. A survey of antibiotic administration practices involving patients with sepsis in UK critical care units. Int J. Clin. Pharm. 2020, 42, 65-71. [CrossRef]

37. Flannery, A.H.; Bissell, B.D.; Bastin, M.T.; Morris, P.E.; Neyra, J.A. Continuous Versus Intermittent Infusion of Vancomycin and the Risk of Acute Kidney Injury in Critically Ill Adults: A Systematic Review and Meta-Analysis. Crit Care Med. 2020, 48, 912-918. [CrossRef]

38. Kim, B.; Lee, M.J.; Moon, S.M.; Park, S.Y.; Song, K.H.; Lee, H.; Park, J.S.; Lee, M.S.; Choi, S.M.; Yeom, J.S.; et al. Current status of antimicrobial stewardship programmes in Korean hospitals: Results of a 2018 nationwide survey. J. Hosp. Infect. 2020, 104, 172-180. [CrossRef] 